\title{
Hydraulic properties of the crystalline basement
}

Ingrid Stober • Kurt Bucher

Erratum to: Hydrogeology Journal, 15:213-224 (2007)

DOI 10.1007/s10040-006-0094-4.

Thanks goes to Steven E. Ingebritsen for pointing out that in the original article there is a discrepancy between equation (2) and the depth versus hydraulic conductivity curve shown on Fig. 8. Inspection of the error showed that equation (2) is incorrectly presented and that the correct equation (2) should be:

$\log k=-1.38 \log z-15.4$

with permeability $\mathrm{k}$ in $\mathrm{m} / \mathrm{s}$ and depth $\mathrm{z}$ in $\mathrm{km}$.

The curve on Fig. 8 is displayed correctly in the paper and also the discussion refers to the correct curve and equation.

Published online: 18 September 2007

C) Springer-Verlag 2007

The online version of the original article can be found at http://dx. doi.org/10.1007/s10040-006-0094-4.

I. Stober (

Geological Survey B.-W.,

Albertstr. 5, 79104, Freiburg, Germany

e-mail: stober@lgrb.uni-freiburg.de

K. Bucher

Institute of Mineralogy and Geochemistry,

University of Freiburg,

Albertstr. 23b, 79104, Freiburg, Germany

e-mail: bucher@uni-freiburg.de 